\title{
Hyper Cross-Linked Polymers as Additives for Preventing Aging of PIM-1 Membranes
}

\author{
Federico Begni ${ }^{1}$, Elsa Lasseuguette ${ }^{2}\left(\mathbb{D}\right.$, Geo Paul $^{1}{ }^{1}$, Chiara Bisio ${ }^{1,3}{ }^{(0)}$, Leonardo Marchese ${ }^{1}$, Giorgio Gatti ${ }^{1, *}$ \\ and Maria-Chiara Ferrari ${ }^{2, *}$ (1) \\ 1 Dipartimento di Scienze e Innovazione Tecnologica, Università degli Studi del Piemonte Orientale \\ “Amedeo Avogadro", Viale Teresa Michel 11, 15121 Alessandria, Italy; federico.begni@uniupo.it (F.B.); \\ geo.paul@uniupo.it (G.P.); chiara.bisio@uniupo.it (C.B.); leonardo.marchese@uniupo.it (L.M.) \\ 2 School of Engineering, University of Edinburgh, Robert Stevenson Road, Edinburgh EH9 3FB, UK; \\ e.lasseuguette@ed.ac.uk \\ 3 CNR-SCITEC Instituto di Scienze e Tecnologie Chimiche "G. Natta", Via C. Golgi 19, 20133 Milano, Italy \\ * Correspondence: giorgio.gatti@uniupo.it (G.G.); m.ferrari@ed.ac.uk (M.-C.F.)
}

Citation: Begni, F.; Lasseuguette, E.; Paul, G.; Bisio, C.; Marchese, L.; Gatti, G.; Ferrari, M.-C. Hyper Cross-Linked Polymers as Additives for Preventing Aging of PIM-1 Membranes. Membranes 2021, 11, 463. https:// doi.org/10.3390/membranes11070463

Academic Editor: Maria Grazia De Angelis

Received: 21 May 2021

Accepted: 17 June 2021

Published: 23 June 2021

Publisher's Note: MDPI stays neutral with regard to jurisdictional claims in published maps and institutional affiliations.

Copyright: (c) 2021 by the authors. Licensee MDPI, Basel, Switzerland. This article is an open access article distributed under the terms and conditions of the Creative Commons Attribution (CC BY) license (https:// creativecommons.org/licenses/by/ $4.0 /)$.

\begin{abstract}
Mixed-matrix membranes (MMMs) are membranes that are composed of polymers embedded with inorganic particles. By combining the polymers with the inorganic fillers, improvements can be made to the permeability compared to the pure polymer membranes due to new pathways for gas transport. However, the fillers, such as hyper cross-linked polymers (HCP), can also help to reduce the physical aging of the MMMs composed of a glassy polymer matrix. Here we report the synthesis of two novel HCP fillers, based on the Friedel-Crafts reaction between a tetraphenyl methane monomer and a bromomethyl benzene monomer. According to the temperature and the solvent used during the reaction (dichloromethane (DCM) or dichloroethane (DCE)), two different particle sizes have been obtained, $498 \mathrm{~nm}$ with DCM and $120 \mathrm{~nm}$ with DCE. The change in the reaction process also induces a change in the surface area and pore volumes. Several MMMs have been developed with PIM-1 as matrix and HCPs as fillers at $3 \%$ and $10 \mathrm{wt} \%$ loading. Their permeation performances have been studied over the course of two years in order to explore physical aging effects over time. Without filler, PIM-1 exhibits the classical aging behavior of polymers of intrinsic microporosity, namely, a progressive decline in gas permeation, up to $90 \%$ for $\mathrm{CO}_{2}$ permeability. On the contrary, with HCPs, the physical aging at longer terms in PIM-1 is moderated with a decrease of $60 \%$ for $\mathrm{CO}_{2}$ permeability. ${ }^{13} \mathrm{C}$ spin-lattice relaxation times (T1) indicates that this slowdown is related to the interactions between HCPs and PIM-1.
\end{abstract}

Keywords: mixed-matrix membranes; physical aging; hyper cross-linked polymer; gas permeation; ${ }^{13} \mathrm{C}$ spin-lattice relaxation times; SS-NMR spectroscopy

\section{Introduction}

Membrane-based materials have played an important role in the field of gas separation [1]. The relatively low energy requirement of membrane processes [2,3] makes them an attractive alternative to more intensive separation processes, such as pressure swing adsorption, chemical absorption and cryogenic [4-7]. A promising area of development for gas separation is the use of hybrid membranes or mixed-matrix membranes (MMMs). MMMs are composite membranes made by combining a filler (dispersed phase) and a polymer matrix (the continuous phase). By using two materials with different transport properties, these membranes have the potential to synergistically combine the easy processability of polymers and the superior gas-separation performance of filler materials, and therefore provide separation properties surpassing the Robeson upper bound [8]. In particular, enhancements have been noticed with nanostructured and highly porous additives, such as metal-organic frameworks, zeolites, carbon nanotubes or hyper crosslinked polymers (HCP) [9-15]. The addition of porous fillers in the continuous phase plays an 
important role in the transport properties of MMMs, providing new pathways for gas transport, hence increasing gas permeability [16-21]. Furthermore, the incorporation of fillers might be a solution to tackle the physical aging of glassy polymers [22-27].

HCPs are a class of high surface area amorphous polymers, which can be obtained either from the post-crosslinking of polystyrene-type precursors in their swollen state, or from the cross-linking of small building blocks, following Friedel-Crafts chemistry [28,29]. The resulting polymers consist of aromatic rings joined together through aliphatic bridges. The formation of a highly interconnected network results in a stable nanoporous structure. HCPs present several advantages, they are stable, tunable, inexpensive, scalable [30] and present high surface areas (1200-2000 $\mathrm{m}^{2} \mathrm{~g}^{-1}$ ) [29], which allow high gas uptakes [31]. For these reasons HCPs are attractive porous solids to be used as fillers within mixed-matrix membranes in order to improve separation performances. Numerous studies show their ability to provide high permeability membranes which can surpass the classical Robeson upper bound. Hou et al. [32] developed MMMs with Poly(1-trimethylsilyl-1-propyne) (PTMSP) matrix and $10 \mathrm{wt} \% \mathrm{HCP}$ as fillers, based on $\alpha, \alpha^{\prime}$-dichloro-p-xylene. Considerable selectivity improvement was achieved thanks to the efficient nanoparticle dispersion and sufficient interaction between the matrix and the filler. The enhancement of gas permeability of MMMs was attributed to the pore channels added by the highly crosslinked fillers which provided additional pathways for gas transport. Lau et al. [33] studied the physical aging of these MMMs. Over time, the $\mathrm{CO}_{2} / \mathrm{N}_{2}$ separation performance increased whilst $\mathrm{CO}_{2}$ permeability remained stable. This selective-aging effect is explained by the retention of fractional free volume (FFV) content by HCP particles. The ${ }^{13} \mathrm{C}$ solid-state NMR spectroscopy showed that the bulky part of the PTMSP chains was immobilized by the HCP. Mitra et al. [34] developed MMMs composed of PIM1 and HCP based on poly(vinyl benzyl chloride). The incorporation of fillers induced an increase of gas permeability due to the higher Brunauer-Emmett-Teller (BET) surface area of HCP $\left(1700 \mathrm{~m}^{2} \mathrm{~g}^{-1}\right)$ compared to PIM1 $\left(750 \mathrm{~m}^{2} \mathrm{~g}^{-1}\right)$. On the contrary, the $\mathrm{CO}_{2} / \mathrm{N}_{2}$ selectivity decreased with the presence of $\mathrm{HCP}$, especially with high amounts of filler (>15 wt \%). Moreover, the presence of HCP retarded the physical aging of the $\mathrm{MMM}$ with a lower decrease in $\mathrm{CO}_{2}$ permeability as compared to PIM-1 alone.

In this paper, we report on the synthesis of new HCPs based on the Friedel-Crafts reaction between a tetraphenyl methane monomer and a bromomethyl benzene monomer. Depending on the solvent used during the reaction, i.e., dichloroethane (DCE) or dichloromethane (DCM), HCPs with different particle sizes were obtained. To the best of our knowledge, the effect of the synthetic conditions on the HCP particle sizes has not been covered in the scientific literature. The synthesized materials have been characterized in terms of their structure and properties. The effect on the membrane gas separation performance over time was investigated when HCPs are used as additives in PIM-1 membranes.

\section{Materials and Methods}

\subsection{Materials Preparation}

The synthesis of PIM- 1 was performed following the procedure reported in literature [35], by mixing anhydrous $\mathrm{K}_{2} \mathrm{CO}_{3}(11.05 \mathrm{~g}, 80 \mathrm{mmol}), 5,5^{\prime}, 6,6^{\prime}$-tetrahydroxy- 3,3,3',3'tetramethyl-1,1'-spirobisindane ( $3.4 \mathrm{~g}, 10 \mathrm{mmol})$, and 2,3,5,6-tetrafluoroterephthalonitrile $(2.0 \mathrm{~g}, 10 \mathrm{mmol})$ in anhydrous dimethylformamide $(65 \mathrm{~mL})$ at $338 \mathrm{~K}$ for $72 \mathrm{~h}$ under an $\mathrm{N}_{2}$ atmosphere. On cooling, the mixture was added to water $(500 \mathrm{~mL})$, and the crude product collected by filtration. Repeated precipitations from methanol gave $4.96 \mathrm{~g}$ (92\% yield) of fluorescent yellow polymer (PIM-1) with a Mw $\sim 87,000 \mathrm{~g} \mathrm{~mol}^{-1}$. 3,3,3',3'-Tetramethyl-1,1'spirobiindane-5,5',6,6'-tetraol and 2,3,5,6- tetrafluorophthalonitrile were purified before use by recrystallization in methanol and ethanol, respectively. Ethanol and methanol were purchased from Fisher Chemicals. Anhydrous dimethylformamide (99.9\%) and 5,5',6,6'-

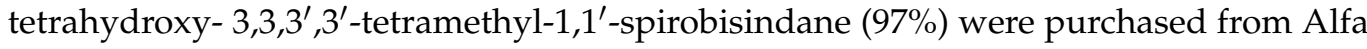


Aesar. Potassium carbonate (99.5\%) and 2,3,5,6-tetrafluoroterephthalonitrile (98\%) were purchased from Fluorochem.

HCPs were named ABT01 and ABT02, AB from aluminum bromide and $\mathrm{T}$ from tetraphenyl methane, while 01 is used for the material obtained by using dichloromethane in the synthetic procedure and 02 for the material obtained using dichloroethane.

Here the synthesis of ABT01 is reported, however the same procedure was employed for the material named ABT02, except that dichloroethane and a temperature of $80{ }^{\circ} \mathrm{C}$ were used instead of dichloromethane at $35^{\circ} \mathrm{C}$.

ABT01 synthetic procedure was carried out in a $250 \mathrm{~mL}$ three-necked bottom flask by adding $1 \mathrm{~g}\left(3.12 \cdot 10^{-3} \mathrm{~mol}\right)$ of tetraphenyl methane (TPM, Capot Chemical Company $(97 \%)$ ) to $90 \mathrm{~mL}$ of dichloromethane (DCM) (Sigma-Aldrich $\geq 99,8 \%$ ) at room temperature. After approximately $10 \mathrm{~min}$ the addition of $10.02 \mathrm{~g}\left(2.8 \times 10^{-2} \mathrm{~mol}\right)$ of the cross-linker 1,3,5-tris(bromomethyl)benzene (Sigma-Aldrich, >97\%) was carried out which after $10 \mathrm{~min}$, which was followed by the addition of $7.46 \mathrm{~g}\left(2.8 \times 10^{-2} \mathrm{~mol}\right)$ of the catalyst aluminum (III) bromide (Sigma-Aldrich, $\geq 98 \%$ ). The reaction mixture was left under stirring for approximately $20 \mathrm{~min}$ and then heated under reflux over night at $308 \mathrm{~K}$. A molar ratio of 1:9:9 between the monomer, the cross-linker and the catalyst was used for the synthesis of both materials. After approximately $22 \mathrm{~h}$ the resulting mixture appeared as a dark brown gel. The reaction was quenched by addition of diluted $\mathrm{HCl}$ with deionized water $(v / v$ 2:1), then the material was washed with ethanol and deionized water. After the washing step, the material was put in an oven at $343 \mathrm{~K}$ for $24 \mathrm{~h}$. ABT01 appears as a brown powder.

The reaction scheme associated with the synthesis of ABT materials is reported in Figure 1.

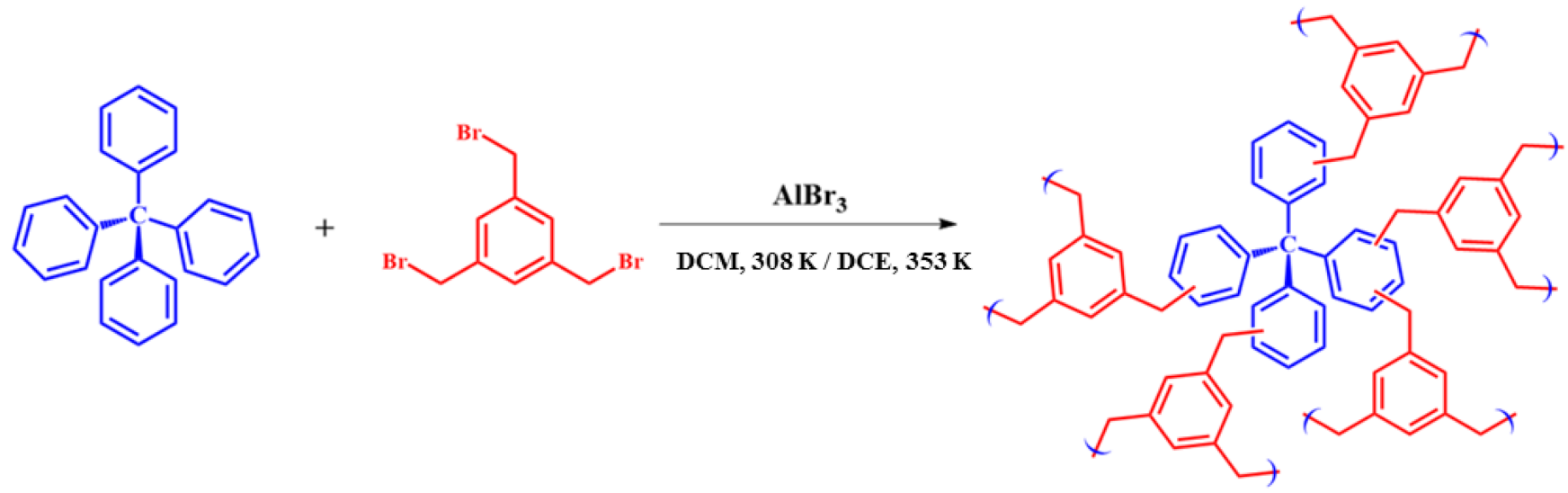

Figure 1. Reaction scheme for the synthesis of ABT hyper crosslinked polymers.

\subsection{Membranes Preparation}

Solution casting [35] at ambient conditions was used to fabricate dense film membranes with a filler content of $3 \mathrm{wt} \%$ and $10 \mathrm{wt} \%$ (with respect to PIM-1 weight). For the preparation of the membranes a suspension of filler (6 mg for $3 \mathrm{wt} \%$ or $20 \mathrm{mg}$ for $10 \mathrm{wt} \%$ ) in $5 \mathrm{~mL}$ of $\mathrm{CHCl}_{3}$ was sonicated with an ultrasound probe (Fisher Scientific, Model CL18, $120 \mathrm{~W}$ ) for $1 \mathrm{~h}$ by using a water bath to maintain the flask at room temperature. Meanwhile, $200 \mathrm{mg}$ of PIM-1 was dissolved in $5 \mathrm{~mL}$ of $\mathrm{CHCl}_{3}$. After complete dissolution, the PIM-1 solution was added to the additive suspension with other $5 \mathrm{~mL}$ of $\mathrm{CHCl}_{3}$. The mixture was then sonicated again for $2 \mathrm{~h}$ at room temperature. The resulting solution was poured into a $5 \mathrm{~cm}$ glass Petri dish. The membrane was allowed to form by slow solvent evaporation for 24-36 h under a fume cupboard. Five membranes were obtained, namely, a pure PIM-1 membrane (PIM-1), two MMMs composed of PIM-1 and ABT01 as a filler at 3 and 10 wt \% named, respectively, PIM1-ABT01-3\% and PIM1-ABT01-10\% and two MMMs composed of PIM-1 and ABT02 as a filler at 3 and $10 \mathrm{wt} \%$, namely, PIM1-ABT02-3\% and PIM1-ABT02-10\%. After the drying steps, the thickness of the membranes was determined 
with a digital micrometer (Mitutoyo). Before performing permeability measurements, the membranes were immersed in methanol for $2 \mathrm{~h}$, followed by a drying step under a fume cupboard for $1 \mathrm{~h}$ and then under vacuum at room temperature overnight. It is well known that the permeability performances of PIM-1 membranes may vary based on the casting conditions (for example, the choice of solvents) and the history of the sample. Alcohol washes away residual casting solvent and provides a comparable starting point for evaluation of different membranes [35].

\subsection{Membranes Characterizations}

Permeation measurements-The permeation properties of the MMMs were tested using the constant volume-variable pressure method in an in-house built time-lag apparatus of which a schematic can be seen in Figure 2 .
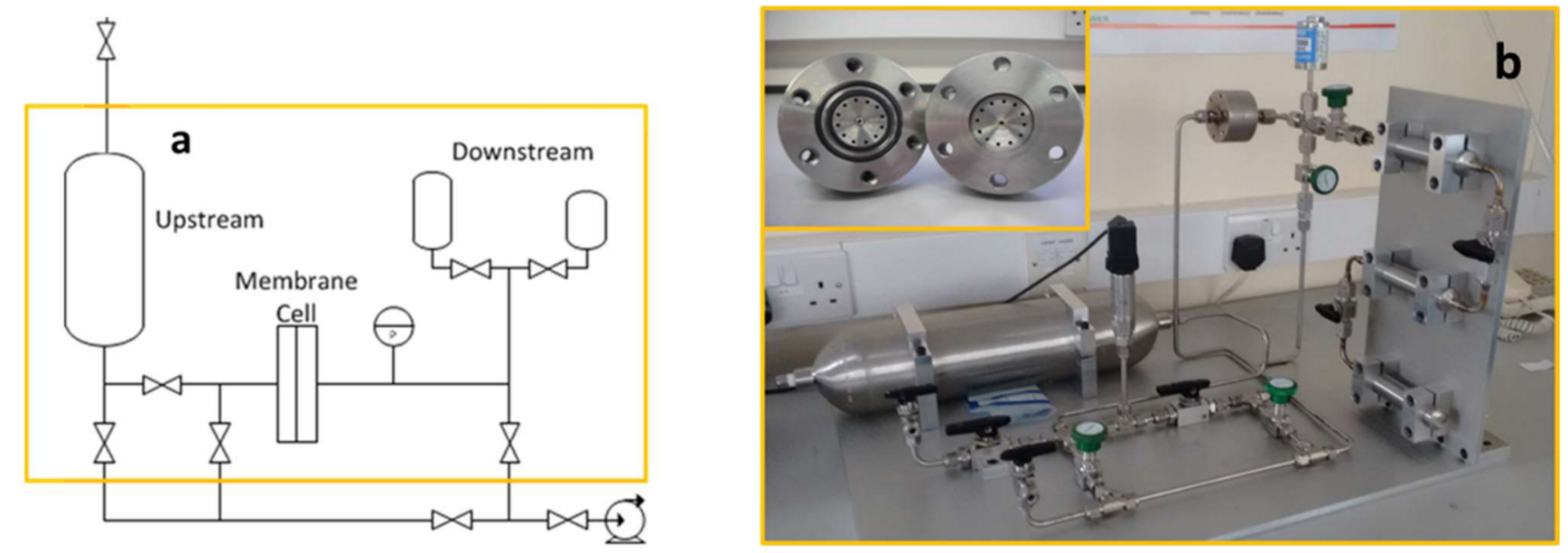

Figure 2. Permeation rig: (a) schematic; (b) rig with the cell.

The permeation cell consists of three main parts, namely, upstream, permeation cell and downstream. The upstream, or feed side, of the permeation cell consists of a controlling valve, a pressure gauge and a $2000 \mathrm{~cm}^{3}$ volume gas reservoir. The sample is positioned in the gas permeation cell and sealed with two rubber O-rings. The downstream volume is fixed and a pressure transducer is used to detect pressure changes.

The permeability is obtained from the evolution of pressure of the downstream side (Brooks Transducer $1000 \mathrm{mBar}, \mathrm{CMC}$ Series). The permeability coefficient, $P$, was determined from the slope of the pressure vs. time curve under steady state condition (Equation (1)).

$$
P(G)=\frac{l}{A} \frac{V_{\text {down }}}{P_{\text {up }} R T}\left(\frac{d P_{\text {down }}}{d t}\right)_{s s}
$$

where $l$ is the membrane thickness, $A$ is the membrane area, $V_{\text {down }}$ is the downstream volume, $P_{u p}$ is the upstream pressure $\left(P_{u p}=1.1 \mathrm{bar}\right), P_{\text {down }}$ is the downstream pressure, $T$ is the temperature recorded during analysis and $R$ is the gas constant.

Before each experiment, the apparatus is vacuum-degassed and a leak rate is determined from the pressure increase in the downstream part.

The ideal selectivity between two gas species $i$ and $j$ is the ratio of the two single-gas permeabilities (Equation (2)).

$$
\alpha_{i j}=\frac{P(i)}{P(j)}
$$

For the aging tests, the initial measurement is performed right after the methanol treatment. The membrane is then stored in a sealed plastic bag at ambient temperature and tested over time. 
Scanning Electron Microscopy (SEM)-The morphological properties of the membranes were examined with a Quanta $200 \mathrm{FEI}$ (Hillsboro, Oregon) operating at $20 \mathrm{kV}$ and equipped with an EDAX (Mahwah, New Jersey) EDS attachment. Before SEM analysis, the samples were prepared by sputtering with a 20-nm layer of gold to form a conductive surface.

$\mathrm{N}_{2}$ physisorption analysis-The specific surface area (SSA) was measured by means of nitrogen adsorption at liquid nitrogen temperature $(77 \mathrm{~K})$ in the pressure range of $1 \times 10^{-6}$ Torr to $1 \mathrm{P} / \mathrm{P}_{0}$ by using an Autosorb-1-MP (Quantachrome Instruments). Prior to adsorption, the samples were outgassed for $3 \mathrm{~h}$ at $423 \mathrm{~K}$, (final pressure lower than $10^{-6}$ Torr). The SSA of the samples was determined by the Brunauer-Emmett-Teller (BET) equation, in a pressure range $0.05-0.15 \mathrm{P} / \mathrm{P}_{0}$ selected to maximize the correlation coefficient of the fitted linear equation. The pore size distribution was calculated by means of the nonlocal density functional theory (NLDFT) method for slit pores.

FT-IR spectroscopy-Infrared spectra were collected on a Thermo Electron Corporation FT Nicolet 5700 spectrometer (resolution $4 \mathrm{~cm}^{-1}$ ). Pellets were prepared by mixing the prepared materials with $\mathrm{KBr}$ (1:10 weight ratio) and placed into an IR cell with $\mathrm{KBr}$ windows permanently connected to a vacuum line (residual pressure: $1 \times 10^{-4} \mathrm{mbar}$ ), allowing all treatments to be performed in situ. Samples were degassed for $3 \mathrm{~h}$, using an oil-free apparatus and grease-free vacuum line.

SS-NMR spectroscopy—Solid-state NMR spectra were acquired on a Bruker Avance III 500 spectrometer and a wide bore 11.7 Tesla magnet with operational frequencies for ${ }^{1} \mathrm{H}$ and ${ }^{13} \mathrm{C}$ of 500.13 and $125.77 \mathrm{MHz}$, respectively. A $4 \mathrm{~mm}$ triple resonance probe, in double resonance mode, with magic angle spinning (MAS) was employed in all the experiments. The as-cast polymer membranes were cut into small pieces so that they could be packed in a $4 \mathrm{~mm}$ Zirconia rotor and were spun at a MAS rate of $12 \mathrm{kHz}$. For the ${ }^{13} \mathrm{C}$ cross-polarization (CP) MAS experiments, the proton radio frequencies (RF) of 55 and $28 \mathrm{kHz}$ were used for initial excitation and decoupling, respectively. During the $\mathrm{CP}$ period the ${ }^{1} \mathrm{H}$ RF field was ramped using 100 increments, whereas the ${ }^{13} \mathrm{C}$ RF field was maintained at a constant level. During the acquisition, the protons were decoupled from the carbons by using a Spinal-64 decoupling scheme. A moderate ramped RF field of $55 \mathrm{kHz}$ was used for spin locking, while the carbon RF field was matched to obtain optimal signal (40 kHz). T1 measurements were performed with a CPXT1 pulse sequence using a $10 \mathrm{~ms}$ spin-lock of $55 \mathrm{kHz}$ and $40 \mathrm{kHz}$ for ${ }^{1} \mathrm{H}$ and ${ }^{13} \mathrm{C}$, respectively, immediately followed by $\pi / 2-\tau-\pi / 2$ sequence on ${ }^{13} \mathrm{C}$ with variable delay $(\tau)$ ranging from 0.1 to $45 \mathrm{~s}$. Spectra were recorded with a spectral width of $42 \mathrm{kHz}$ and 256 transients were accumulated at $298 \mathrm{~K}$. A line broadening of $50 \mathrm{~Hz}$ and zero filling to 2048 points were used. All chemical shifts are reported using $\delta$ scale and are externally referenced to TMS at $0 \mathrm{ppm}$. Data analyses were performed using Bruker software Dynamics Center, version 2.5.6 and T1 curves were obtained by plotting the intensity of the carbon signals versus time. A single exponential decay was used to fit the data using the following equation (Equation (3)):

$$
I_{t}=I_{0} e^{\left(\frac{-t}{T_{1}}\right)}
$$

\section{Results}

3.1. Characterization of the HCPS

\subsubsection{SEM}

In Figure 3, SEM images of ABT materials are reported.

ABT01 and ABT02 appear as aggregates of round-shaped particles. Particle dimensions for ABT01 are $498 \pm 39 \mathrm{~nm}$ while for ABT02 they are $120 \pm 23 \mathrm{~nm}$. From the Energy Dispersive X-Ray elemental analysis (EDX) reported in Table S1, it is seen that ABT materials are mainly composed of carbon, which is expected. The presence of aluminum and bromine is to be attributed to unreacted catalyst species, which is present in higher quantities in ABT01. Bromine could also be present within the polymeric framework as partially unreacted crosslinker species as well as side reaction products. 

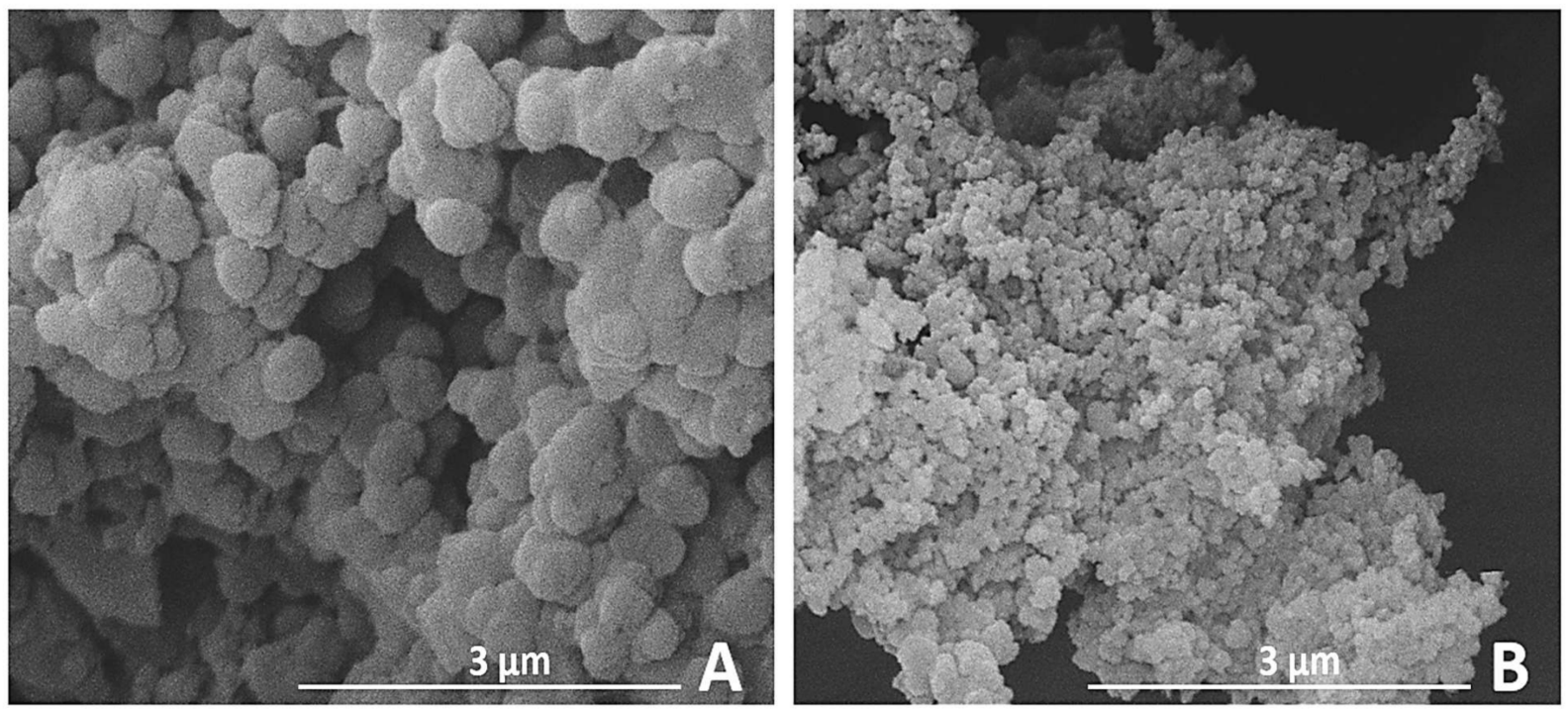

Figure 3. SEM images at 50,000× magnification of ABT01 (A) and ABT02 (B).

\subsection{2. $\mathrm{N}_{2}$ Physisorption Analysis}

The results of the $\mathrm{N}_{2}$ physisorption analysis are reported in Figure 4.
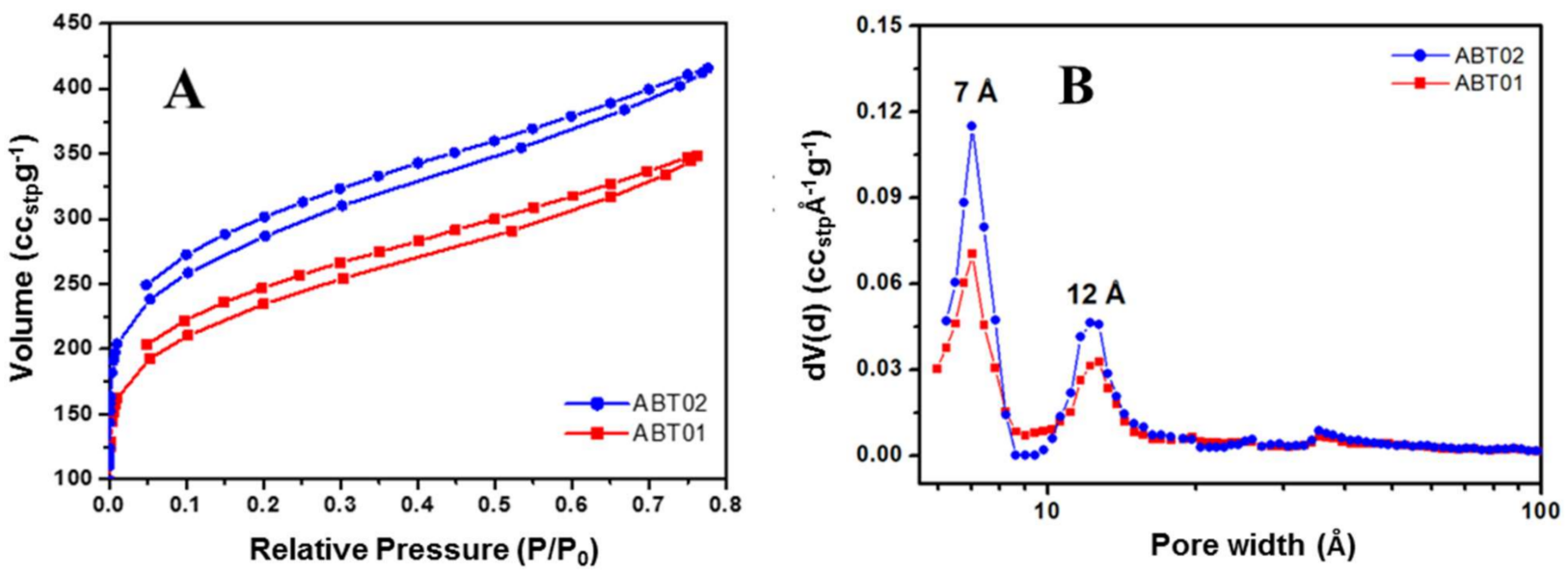

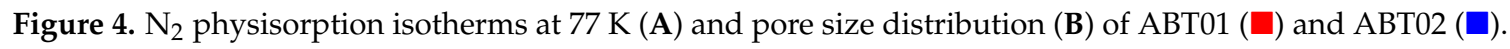

As it can be seen in Figure 4, ABT isotherms (with relative upper pressure of only 0.76-0.77) do not show a horizontal plateau after the initial filling of the micropores, therefore a clear classification of the isotherms cannot be made. In particular, a distinction between type I and II is difficult. A fair amount of gas $\left(>200 \mathrm{~cm}^{3} / \mathrm{g}\right)$ is adsorbed at low relative pressures (up to $0.1 \mathrm{P} / \mathrm{P}_{0}$ ), indicating permanent micro porosity for both materials. Towards higher values of $\mathrm{P} / \mathrm{P}_{0}$ a gradual increase in the amount of adsorbed nitrogen is observed indicating the filling of mesopores in the range between 0.45 and $0.8 \mathrm{P} / \mathrm{P}_{0}$. Open hysteresis loops for both materials are observed for the whole desorption branch, which is consistent with swelling effects of the polymeric network, due to gas sorption [36,37]. The non-reversible desorption at low relative pressures indicates that $\mathrm{N}_{2}$ could either be trapped in pockets or free volume elements with a size comparable to that of the $\mathrm{N}_{2}$ molecule, or swelling of ABT is locking some of the pockets or free volume elements on the time scale of the experiments, or in combination. From the data reported in Table 1 it can be seen that ABT02 possess higher surface area with respect to ABT01, namely, $990 \mathrm{~m}^{2} / \mathrm{g}$ versus $823 \mathrm{~m}^{2} / \mathrm{g}$; in addition, pore volume values associated with both microand mesoporosities are slightly higher in ABT02, which is probably a solvent-induced 
effect since dichloroethane is known to be a particularly suited solvent for the development of high porosity degree in hyper crosslinked polymers [38].

Table 1. Textural properties of ABT materials, assessed via $\mathrm{N}_{2}$ physisorption analysis performed at $77 \mathrm{~K}$.

\begin{tabular}{|c|c|c|c|c|c|c|}
\hline \multirow{2}{*}{ Sample } & \multirow{2}{*}{$\operatorname{SSA}_{\text {BET }}\left(m^{2} / g\right)$} & \multirow{2}{*}{$\mathrm{V}_{\text {Tot }}(\mathrm{cc} / \mathrm{g})$} & \multicolumn{3}{|c|}{$\mathrm{V}_{\text {micro }}(\mathrm{cc} / \mathrm{g})$} & \multirow{2}{*}{$\begin{array}{l}V_{\text {meso }}(\mathrm{cc} / \mathrm{g}) \\
20<\AA<100\end{array}$} \\
\hline & & & Total & $<7 \AA$ & $7<\AA<20$ & \\
\hline ABT01 & 823 & 0.52 & 0.28 & 0.08 & 0.20 & 0.24 \\
\hline ABT02 & 990 & 0.61 & 0.35 & 0.10 & 0.25 & 0.26 \\
\hline
\end{tabular}

\subsubsection{FT-IR Spectroscopy}

IR spectra of ABT materials are reported in Figure 5 with the assignments of the IR absorption bands in Table 2 .

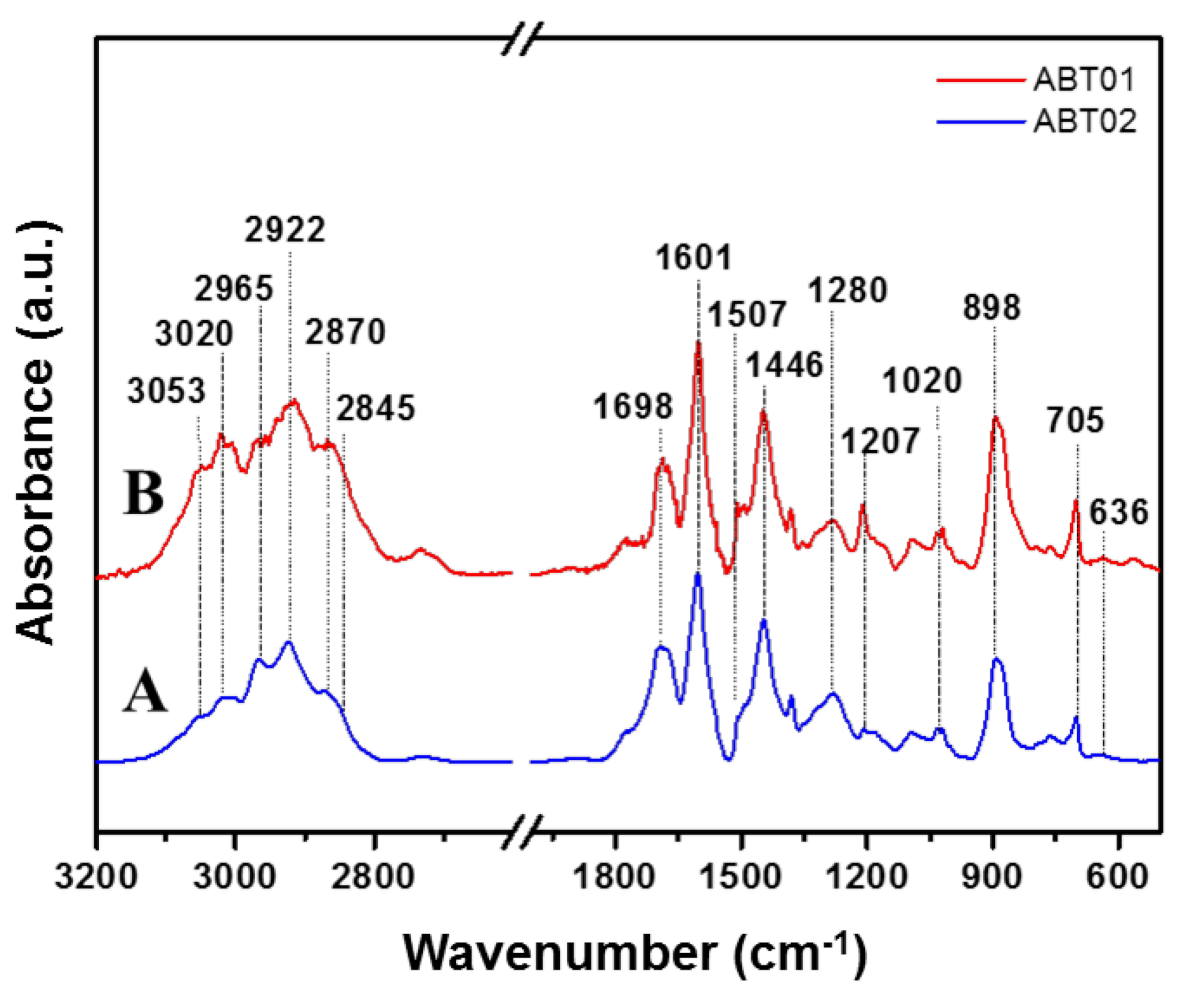

Figure 5. Infrared spectra of $\mathrm{ABT} 01-(\mathrm{A})$ and $\mathrm{ABT} 02-(\mathbf{B})$ acquired under vacuum conditions (minimum pressure below $10^{-4} \mathrm{mbar}$ ) and beam temperature. Prior to analysis, the samples were treated at $423 \mathrm{~K}$ under vacuum $\left(10^{-4}\right.$ mbar) for three hours.

The IR spectra of ABT materials present signals in the ranges $3200-2800 \mathrm{~cm}^{-1}$ and $1750-400 \mathrm{~cm}^{-1}$. In the high wavenumber region, broad bands are found centered at 3053 , $3020,2965,2922,2870$ and $2845 \mathrm{~cm}^{-1}$. The signals at 3053 and $3020 \mathrm{~cm}^{-1}$ are respectively assigned to the asymmetric and symmetric stretching of aromatic $\mathrm{C}-\mathrm{H}$ groups $[39,40]$. Between 3000 and $2800 \mathrm{~cm}^{-1}$, the signals of aliphatic C-H stretching vibrations are found. In particular, the band at $2965 \mathrm{~cm}^{-1}$ is assigned to the C-H asymmetric stretching mode of methyl groups $[37,39,40]$ while the band at $2922 \mathrm{~cm}^{-1}$ is assigned to the asymmetric stretching mode of the $-\mathrm{CH}_{2}$ - group $[39,40]$. The corresponding symmetric stretching vibrations are found at $2870 \mathrm{~cm}^{-1}$ for the methyl group and at $2845 \mathrm{~cm}^{-1}$ for the methylene group $[37,39,40]$. The ratio between the intensity of the aliphatic over aromatic $\mathrm{C}-\mathrm{H}$ stretching modes bands is higher for the ABT02 with respect to ABT01, which could be 
an indication of a more crosslinked network. In the low frequency region, a series of signals is found, and assignments have been made for the main absorption bands, namely, the bands at 1698, 1601, 1507, 1446, 1270, 1020, 898 and $705 \mathrm{~cm}^{-1}$. Between 1700 and approximately $1200 \mathrm{~cm}^{-1}$, signals associated with stretching modes of $-\mathrm{C}=\mathrm{C}$ - bonds are found $[39,40]$. The band at $1698 \mathrm{~cm}^{-1}$ is associated with hindered vibrations of the aromatic rings, probably due to high crosslinking degree of the polymeric framework [41]. The relative intensity of this signal slightly increases for ABT02 with respect to ABT01. This can be linked to higher interconnectivity of the polymeric network of ABT02, probably as a consequence of the higher temperature adopted during the synthetic procedure which accelerated the crosslinking reaction. Additional evidence of the higher crosslinking degree for ABT02 is also the lower intensity of the signal at $1207 \mathrm{~cm}^{-1}$ assigned to skeletal C-C bond vibrations $[39,40]$. The absence of a sharp peak around $1500 \mathrm{~cm}^{-1}$ and the presence of the intense signal at $1601 \mathrm{~cm}^{-1}$ are indications of possible predominant meta substitution of the aromatic rings, which is expected when $\mathrm{AlBr}_{3}$ is used in the synthetic procedure [39,40,42].

Table 2. Assignments of the main IR absorption bands of ABT materials.

\begin{tabular}{|c|c|}
\hline Band Positions ( $\left.\mathrm{cm}^{-1}\right)$ & Assignments $[39,40]$ \\
\hline 3053 & $v_{\text {As }}$ Aromatic C-H \\
\hline 3020 & $v_{\mathrm{S}}$ Aromatic C-H \\
\hline 2965 & $v_{\text {As }}$ Aliphatic $\mathrm{C}-\mathrm{H}\left(-\mathrm{CH}_{3}\right)$ \\
\hline 2922 & $v_{\text {As }}$ Aliphatic $\mathrm{C}-\mathrm{H}\left(-\mathrm{CH}_{2}-\right)$ \\
\hline 2870 & $v_{\mathrm{S}}$ Aliphatic C-H $\left(-\mathrm{CH}_{3}\right)$ \\
\hline 2845 & $v_{\mathrm{S}}$ Aliphatic $\mathrm{C}-\mathrm{H}\left(-\mathrm{CH}_{2}-\right)$ \\
\hline 1280 & $v$ skeletal -C-C- \\
\hline $1700-1210$ & Collective stretching vibrations of poly-substituted benzene rings \\
\hline $900-700$ & Collective bending vibrations of poly-substituted benzene rings \\
\hline 636 & $v$ aliphatic $\mathrm{C}-\mathrm{Br}\left(-\mathrm{CH}_{2} \mathrm{Br}\right)$ \\
\hline
\end{tabular}

In-plane bending modes of aromatic $\mathrm{C}-\mathrm{H}$ groups are found between 1225 and $950 \mathrm{~cm}^{-1}$ [40] while out-of-plane bending modes are found between 1020 and $700 \mathrm{~cm}^{-1}$ [40]. The presence of the intense signal centered at $898 \mathrm{~cm}^{-1}$ may be interpreted as a sign of 1,3 substitution of the aromatic ring [40].

Between 700 and $600 \mathrm{~cm}^{-1}$ the stretching vibrations of the $\mathrm{C}-\mathrm{Br}$ bond are found. For ABT01, a weak signal at $636 \mathrm{~cm}^{-1}$ is found, which indicates that a small amount of bromine is directly linked to the polymeric network, probably as $-\mathrm{CH}_{2} \mathrm{Br}$ groups, since the aromatic $\mathrm{C}-\mathrm{Br}$ bond stretching vibrations are found around $680 \mathrm{~cm}^{-1}$ [40]. For ABT02, only very weak broad bands are observed in the region of the $\mathrm{C}-\mathrm{Br}$ stretching modes.

\subsubsection{SS-NMR Spectroscopy}

In Figure $6,{ }^{13} \mathrm{C}$ CPMAS NMR spectra of the two samples are reported.

Peaks associated with aromatic carbons are found in the region between 150 and $120 \mathrm{ppm}$. Around $142 \mathrm{ppm}$ the signal is associated with both the carbon directly attached to the central quaternary carbon and the carbon directly attached to the methylene group of the crosslinker [43].

Aromatic carbons associated with C-H groups are found at 134 and 128 ppm [43]. The central quaternary carbon of the monomer unit is found at $58 \mathrm{ppm}$ while around $35 \mathrm{ppm}$ the carbons associated with the methylene group of the crosslinker are found [43]. In the region around 40-35 ppm the signals associated with $-\mathrm{CH}_{2} \mathrm{Br}$ can also be found [44]. Carbons associated with methyl groups are found around 17 and 12 ppm [37,43]. It is interesting to observe the presence of these functional groups since they are not present in either the monomer or crosslinker. This finding is also confirmed by the FT-IR analysis (vide supra). 
As a possible explanation, the presence of ethyl groups can be a consequence of a small fraction of dichloroethane molecules reacting with the catalyst while methyl groups could be explained via mechanisms involving the carbocationic sites of the crosslinker. This type of functional group was previously found in hyper crosslinked aromatic polymers and derives from secondary reactions that can occur in the presence of dichloroethane solvent [43].

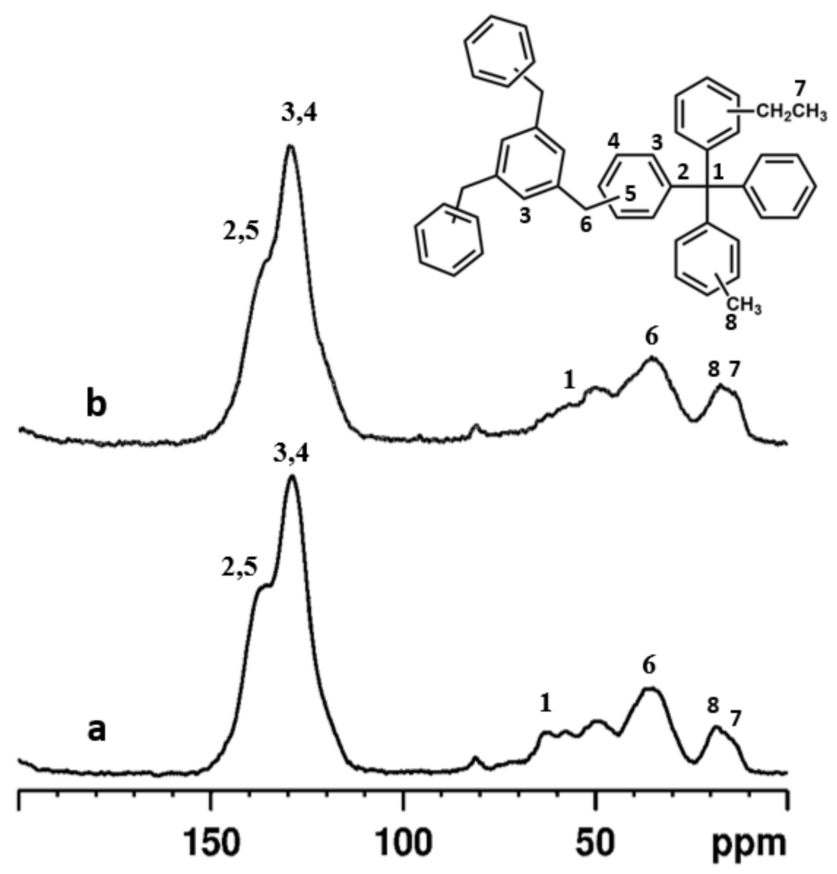

Figure 6. ${ }^{13} \mathrm{C}$ CPMAS NMR spectra of ABT01 (a) and ABT02 (b).

\subsection{Membranes Characterization}

Membrane photographs of PIM-1 and PIM-1-ABT0 membranes are presented in Figure 7.
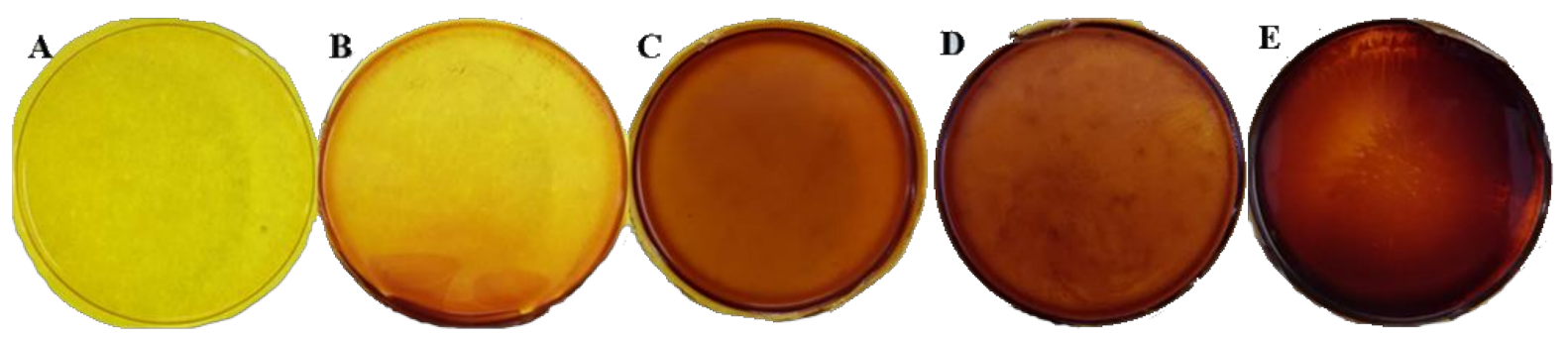

Figure 7. Pristine PIM-1 membrane (A), PIM1-ABT01 (3 wt \%) (B), PIM-ABT02 (3 wt \%) (C), PIM1-ABT01 (10 wt \%) (D) and PIM1-ABT02 (10 wt \%) (E).

As Figure 7 shows, good dispersion of the filler within the membrane has been obtained. No aggregates were visible.

\subsubsection{Permeability Measurements}

Freshly cast membranes

Table 3 shows the separation performances of PIM- 1 and the four MMMs after MeOH treatment, at $\mathrm{t}_{0}$.

The permeation data of PIM-1 are in the range of those reported in the literature [35]. PIM-1 is highly permeable to $\mathrm{CO}_{2}$ and presents a reasonable $\mathrm{CO}_{2} / \mathrm{N}_{2}$ selectivity as well. By adding $3 \mathrm{wt} \%$ of the filler ABT02, a decrease of $35.2 \%$ in $\mathrm{CO}_{2}$ permeability with the 
$\mathrm{CO}_{2} / \mathrm{N}_{2}$ selectivity almost unaffected is observed. Addition of $10 \mathrm{wt} \%$ of ABT02 results in a drop of $44 \%$ in $\mathrm{CO}_{2}$ permeability while an increase in selectivity from 15 to 18 is also observed. The decline in permeability could have multiple sources and it might be due to densification of the PIM-1 polymeric chain, filling of fractional free volumes by the HCP particles or a partial blockage of the HCP pores by polymer chains [45]. Another possible explanation could be that non-covalent interactions between the fillers and the PIM-1 matrix do not allow for the complete regeneration of the MMMs via methanol treatment. For the MMM sample prepared with the addition of $10 \mathrm{wt} \%$ of ABT01, we have a similar separation performance decline of $34 \%$ in $\mathrm{CO}_{2}$ permeability, but also a drop of $13 \%$ in selectivity. This drop might be explained as for ABT02 with a possible rigidification of the polymeric chain due to the filler, by occupation of fractional free volume within the PIM-1 matrix by addition of the fillers or by a partial blockage of the ABT01 pores by PIM-1 chains. The addition of ABT01 at low content stands out as it induces an increase in $\mathrm{CO}_{2}$ permeability and selectivity. The addition of ABT01 with a $10 \mathrm{wt} \%$ loading causes a drop in the selectivity while the addition of ABT02 with the same loading causes the $\mathrm{CO}_{2} / \mathrm{N}_{2}$ selectivity to increase. This may be ascribed to particle dimension effects, meaning that the larger particles associated with ABT01 could partially disrupt chain packing in the PIM-1 matrix resulting in the formation of non-selective gas diffusion pathways.

Table 3. Permeation data for PIM-1, PIM-ABT01 (3 and 10\% wt), PIM-ABT02 (3\% and 10\% wt) at $\mathrm{t}_{0}$ (MeOH treatment). (1 Barrer $\left.=10^{-10} \mathrm{~cm}^{3}(\mathrm{STP}) \cdot \mathrm{cm} \cdot \mathrm{cm}^{-2} \cdot \mathrm{s}^{-1} \cdot \mathrm{cmHg}^{-1}\right)$.

\begin{tabular}{cccc}
\hline \multirow{2}{*}{ Filler } & \% wt & $\begin{array}{c}\text { Permeability } \mathbf{C O}_{\mathbf{2}} \\
(\text { Barrer })( \pm \mathbf{5} \%)\end{array}$ & Selectivity $\mathbf{C O}_{\mathbf{2}} / \mathbf{N}_{\mathbf{2}}$ \\
\hline \multirow{2}{*}{ ABT01 } & 0 & 13,400 & 15 \\
\cline { 2 - 4 } & 3 & 14,700 & 18 \\
\hline \multirow{2}{*}{ ABT02 } & 10 & 8800 & 13 \\
\cline { 2 - 4 } & 0 & 13,400 & 15 \\
\hline & 3 & 8690 & 14 \\
\hline
\end{tabular}

Aging behavior-Permeability measurements were conducted over the course of approximately two years. Measurements were performed after leaving the sample under vacuum over-night at room temperature.

Figure 8 summarizes the aging characteristics of the pristine PIM- 1 and MMMs between $t_{0}$ and $t_{f}$. The mixed matrix containing $3 \%$ of ABT01 was only measured up to 250 days.

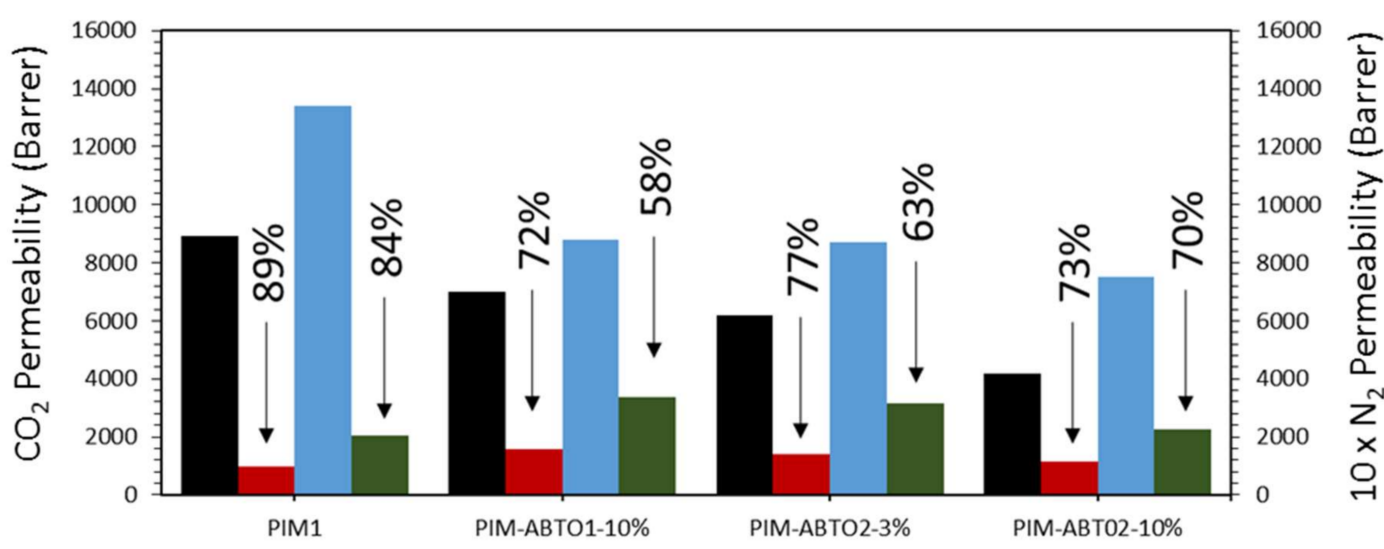

Figure 8. Permeability values and loss of permeability in \% of mixed-matrix membranes (MMMs). on $\mathrm{t}_{0} ;(\square) \mathrm{N}_{2}$ permeability on $\mathrm{t}_{\mathrm{f}} ;(\square) \mathrm{CO}_{2}$ permeability on $\mathrm{t}_{0} ;(\square) \mathrm{CO}_{2}$ permeability on $\mathrm{t}_{\mathrm{f}}(850$ days). 
In Figure 9 the initial drop in the normalized permeation data is reported as a function of time over approximatively the first year of aging.

All the samples present a drop in permeability with time. Aging effects on all samples are clearly visible in the first few days after methanol treatment regardless of the size of the particles (i.e., ABT01 or ABT02) or the concentration of the filler (i.e., 3 or $10 \mathrm{wt} \%$ ). PIM-1 displays the classical aging behavior exhibited by polymers of intrinsic microporosity $[46,47]$, namely, a progressive drop in the permeation capacity associated with both $\mathrm{CO}_{2}$ and $\mathrm{N}_{2}$ caused by the collapse of free volume [46]. After approximatively one year of aging, $\mathrm{CO}_{2}$ permeability of pure PIM- 1 decreases by $85 \%$ with respect to $t_{0}$ value, while for $\mathrm{N}_{2}$ it reduces by $90 \%$ of the initial permeability, hence an increase in selectivity over time towards $\mathrm{CO}_{2}$ is observed.
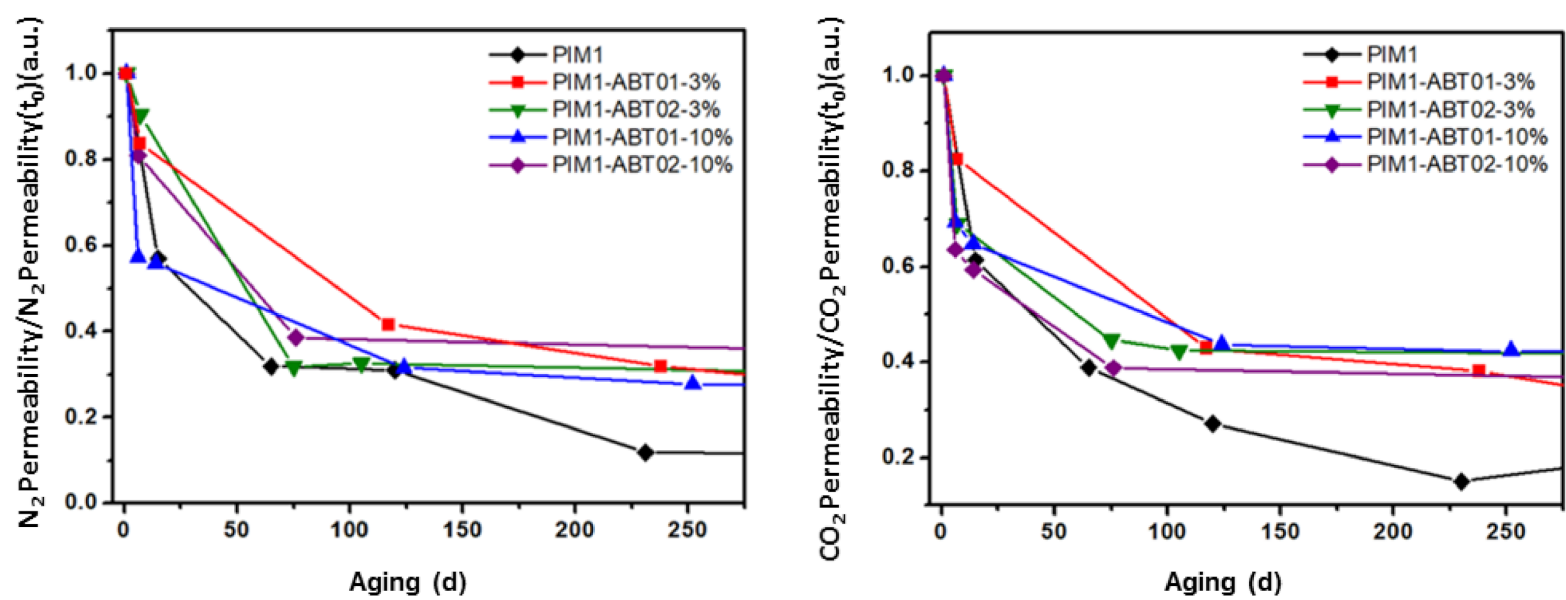

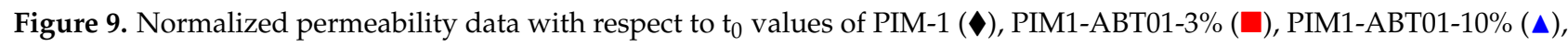
PIM1-ABT02-3\% ( $\nabla)$, PIM1-ABT02-10\% ( $)$, as function of time over 1 year. Lines are drawn to guide eye.

As shown in Figure 9, the nanocomposite membranes show a better resistance to the aging than the pristine membrane at 200 days where the permeability drop appears to have stopped. The addition of the ABT compounds leads to an arrest in polymer aging and permeability loss. The particles incorporated within the polymer prevent the collapse of the free volume $[22,25,27,33,34]$. The HCPs possess a rigid network due to the high level of crosslinks which prevents the collapse of the structure. The PIM1-ABT01-3\% membrane shows a different behavior compared to the other samples, with a slower rate of aging more similar to PIM-1 with aging progressing even when the other samples have stabilized. In Table 4 the final permeability at $\sim 850$ days is reported for the mixed matrices that had stopped aging, confirming that the insertion of the HCPs has prevented further aging compared to the one-year mark and with no significant difference between the filler produced with a different solvent (i.e., of different particle sizes) or the concentration of the filler. Only $3 \%$ of the filler ABT02 is sufficient to inhibit aging compared to the pristine PIM-1.

Table 4. $\mathrm{CO}_{2}$ and $\mathrm{N}_{2}$ permeability coefficients and selectivity data of PIM-1, PIM1-ABT01-3\%, PIM1-ABT01-10\%, PIM1-ABT02-3\%, PIM1-ABT02-10\% at $t_{0}$ and $t_{f}$.

\begin{tabular}{ccccccc}
\hline \multirow{2}{*}{ Membrane } & \multicolumn{2}{c}{$\begin{array}{c}\mathbf{P}_{\mathrm{CO} 2} \\
\text { (Barrer) }\end{array}$} & \multicolumn{2}{c}{$\begin{array}{c}\mathbf{P}_{\mathbf{N} 2} \\
\text { (Barrer) }\end{array}$} & \multicolumn{2}{c}{ Selectivity $\mathbf{C O}_{\mathbf{2}} / \mathbf{N}_{\mathbf{2}}$} \\
\cline { 2 - 7 } & $\mathbf{t}_{\mathbf{0}}$ & $\mathbf{t}_{\mathbf{f}}$ & $\mathbf{t}_{\mathbf{0}}$ & $\mathbf{t}_{\mathbf{f}}$ & $\mathbf{t}_{\mathbf{0}}$ & $\mathbf{t}_{\mathbf{f}}$ \\
\hline PIM-1 & 13,400 & 2040 & 890 & 100 & 15 & 21 \\
\hline PIM1-ABT01-10\% & 8800 & 3390 & 700 & 160 & 13 & 21 \\
\hline PIM1-ABT02-3\% & 8690 & 3170 & 620 & 140 & 14 & 22 \\
\hline PIM1-ABT02-10\% & 7500 & 2270 & 420 & 110 & 18 & 20 \\
\hline
\end{tabular}




\subsubsection{SS-NMR ${ }^{13} \mathrm{C}$ T1 Measurements}

The typical ${ }^{13} \mathrm{C}$ CPMAS NMR spectra for PIM-1 and PIM1-ABT-based as-cast membranes are shown in Figure 10. The only visible difference between these spectra is that in the MMMs we see an additional broad peak due to aromatic carbons (highlighted by red arrow) belonging to the ABT fraction. The ${ }^{13} \mathrm{C}$ resonances originating from the PIM-1 backbone have enough peak resolution and intensities such that the ${ }^{13} \mathrm{C}$ spin-lattice relaxation time $\left(\mathrm{T}_{1}\right)$ measurements have been carried out. The influence of additives on the relaxation behavior of individual carbons in PIM-1 can reveal the molecular level dynamics in the polymer membranes.
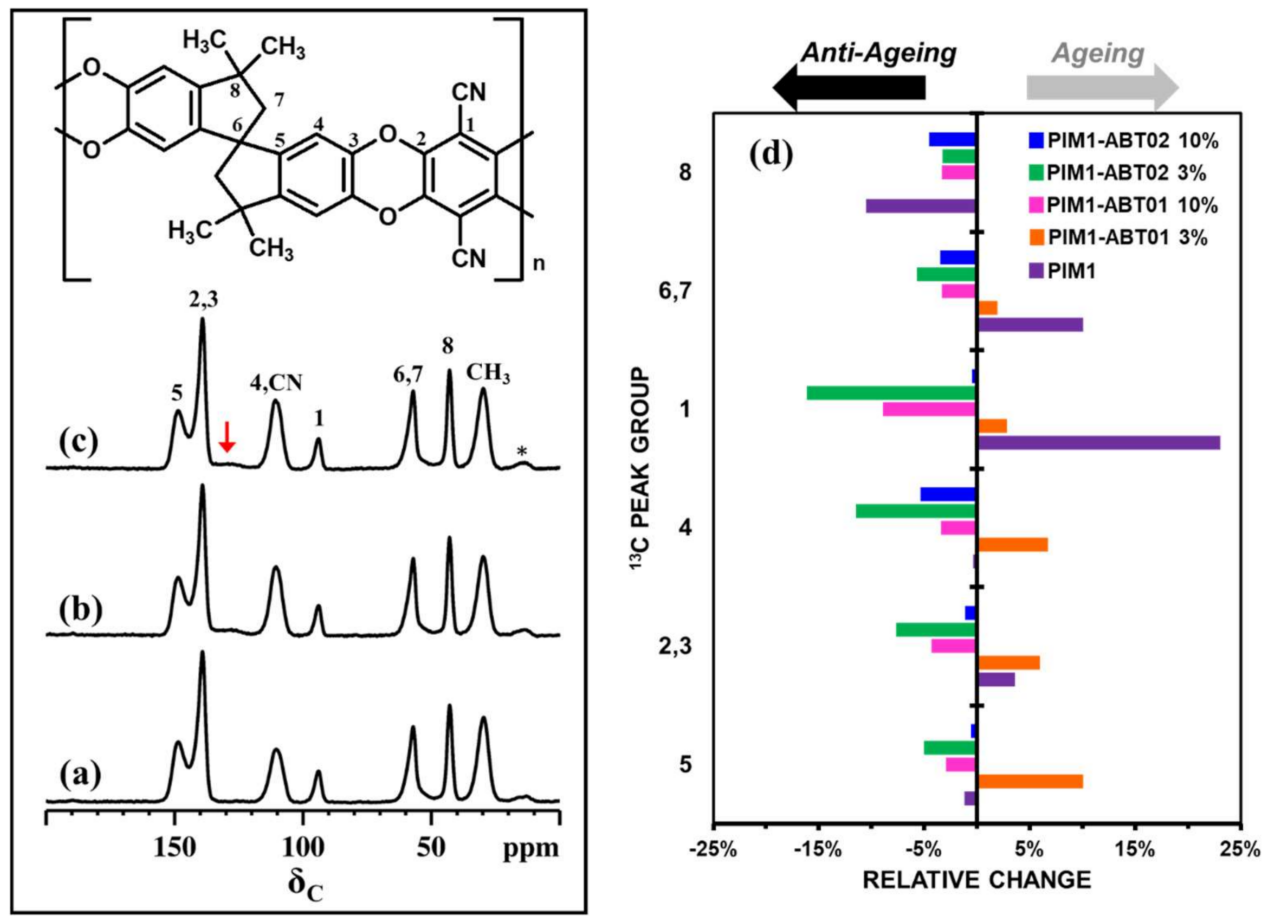

Figure 10. ${ }^{13} \mathrm{C}$ CPMAS NMR spectra of various PIM-1 based membranes: PIM-1 (a), PIM1-ABT01 10\% (b) and PIM1-ABT02 10\% (c). The spectra were recorded using a magic angle spinning (MAS) rate of $12 \mathrm{kHz}$ and a CP contact time of $10 \mathrm{~ms} .{ }^{*}$ Denotes spinning sidebands. Bar chart (d) representing percentage changes in $T_{1}$ relaxation times of chemical groups assigned in (c) between $t_{12}$ (1-year aging) and $\mathrm{t}_{0}(\mathrm{MeOH}$ treatment).

The $T_{1}$ values are related to the mobility/rigidity of specific carbon atoms within the polymer and the ${ }^{13} \mathrm{C}$ relaxation studies allow one to estimate the aging in polymer membranes. We have recorded the ${ }^{13} \mathrm{C}_{1}$ values, at ambient temperature, on the freshly cast $\left(t_{0}\right)$ as well as on the one-year aged $\left(t_{12}\right)$ membranes. The relative changes $\left(\left(t_{12}-t_{0}\right) / t_{0}\right)$ in the ${ }^{13} \mathrm{C}$ spin-lattice relaxation time values, which have been evaluated to estimate the aging behavior in PIM1 based membranes, are shown in Figure 10d.

As the aging starts, an increase in the $\mathrm{T}_{1}$ values for the polymer carbons is expected due to the rigidification of the polymer backbone and the gradual reduction in its excess free volume $[22,25]$. This is the case in the PIM-1 membrane where the backbone carbons $(\mathrm{C} 1, \mathrm{C} 2, \mathrm{C} 3, \mathrm{C} 6$ and $\mathrm{C} 7)$ have longer $\mathrm{T}_{1}$ values at $t_{12}$. Similarly, uniformly higher spin-lattice relaxation times at $t_{12}$ were detected for all carbons in the PIM1-ABT01-3\% aged composite membrane. These results show that as the polymer membrane ages, the relaxation times of polymer carbons increases, and the chain mobility decreases due to densification. These results confirm the similar trend in permeability over time for the PIM1-ABT01-3\% and pristine PIM-1 membranes.

As far as the other composite membranes (namely, PIM1-ABT01-10\%, PIM1-ABT02$3 \%$, and PIM1-ABT-02 10\%) are concerned, significant reductions in the $\mathrm{T}_{1}$ values at $t_{12}$ for 
all carbons have been noted. In particular, carbons $\mathrm{C} 1-\mathrm{C} 4$ show the significant decrease in ${ }^{13} \mathrm{C} \mathrm{T}_{1}$ values between $t_{0}$ and $t_{12}$, evidencing the preferable influence of additives on those aromatic carbons. These reductions in the spin-lattice relaxation times on the aged membranes are due to greater molecular mobility of the polymer backbone carbons because of their preferential interactions with ABT components. Previous studies [25,33] have shown that Porous Aromatic Frameworks (PAF) based additives have moderated the aging in PIM-1-based MMMs. Here ABT-based additives should make non-covalent interactions with the PIM-1 backbone, thus preventing the compactification of the polymer chains. On average, weak non-covalent interactions are expected to be at play between the filler and the PIM-1 matrix. Shorter $\mathrm{T}_{1}$ values could be observed, as is in the case of the present study, if these interactions could result in an enhancement of the mobility of chain backbones, which would also cause a freeing of some fractional free volume, in turn increasing the segmental motion further. As the excess free volume gradually increases, physical aging is diminished in the longer terms in the remaining three ABT-based composite membranes (PIM1-ABT01-10\%, PIM1-ABT02-3\%, and PIM1-ABT02-10\%).

In summary, although the carbon atoms in PIM-1 can be categorized into flexible and bendable units or bulky units or contortion points, their effective packing can lead to diminution of chain motions. On the contrary, when a PIM-1 membrane is cast with the addition of $\mathrm{ABT}$ as a filler, new pathways for the gas transport could be generated. In addition, the intimate mixing at the molecular level introduces non-covalent interactions which lead to the retention of fractional free volume in the MMMs. Since the relaxation behavior of aromatic carbons in PIM- 1 are mostly influenced, $\pi-\pi$ stacking-based interactions can be envisaged as the ABT additive belongs to a hyper-crosslinked aromatic polymer system.

The difference in aging behavior between ABT01 and ABT02 MMMs could be ascribed in part to the difference in textural properties between the two fillers, however the difference in particles size between the two fillers could lead to higher contact surface for ABT02, being the fillers with the smaller particles (see SEM characterization).

The interactions induce anti-aging properties into PIM-1 membranes revealing the chemical compatibility between the ABT polymer and PIM-1. Consequently, physical aging at longer terms in PIM-1 is moderated by the presence of ABT-based additives.

\section{Conclusions}

Novel hyper cross-linked polymers (HCPs) named ABT01 and ABT02, based on tetraphenyl methane and 1,3,5-tris(bromomethyl)benzene, were successfully synthesized and characterized via FT-IR and ${ }^{13}$ C-SS-NMR spectroscopy, via scanning electron microscopy (SEM) and via $\mathrm{N}_{2}$ physisorption analysis at $77 \mathrm{~K}$. By changing the solvent and the temperature of the reaction mixture, control over the particle dimension could be exerted. Dichloroethane and a higher temperature resulted in higher specific surface area and pore volumes.

ABT materials were tested as fillers for the production of PIM- 1 based mixed-matrix membranes for $\mathrm{CO}_{2}$ and $\mathrm{N}_{2}$ gas separation applications. Four MMMs were obtained by adding ABT01 and ABT02 with a 3 and $10 \mathrm{wt} \%$ loading with respect to PIM-1. The addition of the fillers causes a reduction in permeability performances with respect to pure PIM-1 towards both $\mathrm{CO}_{2}$ and $\mathrm{N}_{2}$ at $\mathrm{t}_{0}$, right after methanol treatment. In terms of $\mathrm{CO}_{2} / \mathrm{N}_{2}$ selectivity, only PIM1-ABT01-3\% and PIM1-ABT02-10\% showed higher values with respect to pure PIM-1 while the other samples showed a slight decrease in selectivity.

With aging, all the membranes showed a reduction in gas permeability. However, while pure PIM-1 showed a reduction of 85 and $90 \%$ for $\mathrm{CO}_{2}$ and $\mathrm{N}_{2}$ permeability, respectively, MMMs exhibited a visible slowdown of the aging rate after two months from $t_{0}$. After almost three years of aging, MMMs retained approximately $40 \%$ of the initial $\mathrm{CO}_{2}$ permeability and approximately $25 \%$ of the $\mathrm{N}_{2}$ permeability with respect to $\mathrm{t}_{0}$ values, hence an increase in $\mathrm{CO}_{2} / \mathrm{N}_{2}$ selectivity was also observed.

${ }^{13} \mathrm{C}$ spin-lattice relaxation times $\left(\mathrm{T}_{1}\right)$ allowed monitoring of molecular-level dynamics and degree of flexibility of polymers in membranes. It was found that for the pure PIM-1 
membrane and the MMM containing 3\% ABT01, $\mathrm{T}_{1}$ values increased over time with respect to $T_{1}$ values measured at $t 0$. Longer $T_{1}$ values are a sign of reduction of fractional free volumes within the PIM-1 matrix, due to physical aging. However, for the other MMMs the opposite trend was noticed and shorter $T_{1}$ values were observed with respect to those measured for the freshly cast membranes. This indicates that interactions between the PIM-1 polymer matrix and the ABT fillers provide a way to slow down physical aging for PIM-1-based gas separation membranes.

Supplementary Materials: The following are available online at https:/ /www.mdpi.com/article/10 $.3390 /$ membranes11070463/s1, Table S1: Elemental analysis performed via EDX spectroscopy on ABT01 and ABT02 materials. Five measurements were performed on each sample and the mean values are here reported.

Author Contributions: Conceptualization, M.-C.F., L.M., C.B. and G.G.; formal analysis, F.B., G.P., E.L.; investigation, F.B., G.P. and E.L.; writing—original draft preparation, F.B., G.P. and E.L.; writingreview and editing, M.-C.F., G.G., C.B. and L.M.; supervision, M.-C.F., G.G. and C.B. All authors have read and agreed to the published version of the manuscript.

Funding: This research received no external funding.

Institutional Review Board Statement: Not applicable.

Informed Consent Statement: Not applicable.

Data Availability Statement: The data presented in this study are available on request from the corresponding author. The data are not publicly available due to privacy.

Conflicts of Interest: The authors declare no conflict of interest.

\section{References}

1. Credence Research. Gas Separation Membranes Market by Type, By Application-Growth Future Prospects and Competitive Analysis, 2016-2024; Credence Research: San Jose, CA, USA, 2017.

2. Abanades, J.; Arias, B.; Lyngfelt, A.; Mattisson, T.; Wiley, D.; Li, H.; Ho, M.; Mangano, E.; Brandani, S. Emerging $\mathrm{CO}_{2}$ capture systems. Int. J. Greenh. Gas Control. 2015, 40, 126-166. [CrossRef]

3. Ho, M.T.; Allinson, G.W.; Wiley, D.E. Reducing the Cost of $\mathrm{CO}_{2}$ Capture from Flue Gases Using Membrane Technology. Ind. Eng. Chem. Res. 2008, 47, 1562-1568. [CrossRef]

4. Duong, S. White Paper: Cost Effective Alternative to Distillation for Olefin Purification and Extraction. Available online: https:/ / www.imtexmembranes.com/cost-effective-alternative-to-distillation-for-olefin-purification-and-extraction (accessed on 1 January 2019).

5. Puri, P.S. Chapter Commercial Applications of Membranes in Gas Separations. In Membrane Engineering for the Treatment of Gases: Gas-Separation Problems with Membranes; Royal Society of Chemistry (RSC): Cambridge, UK, 2011; pp. 215-244.

6. Sanders, D.F.; Smith, Z.P.; Guo, R.; Robeson, L.M.; McGrath, J.E.; Paul, D.R.; Freeman, B.D. Energy-efficient polymeric gas separation membranes for a sustainable future: A review. Polymer 2013, 54, 4729-4761. [CrossRef]

7. Robinson, S.; Jubin, R.; Choate, B. Materials for Separation Technology: Energy and Emission Reduction Opportunities; U.S. Department of Energy: Washington, DC, USA, 2005.

8. Robeson, L.M. The upper bound revisited. J. Membr. Sci. 2008, 320, 390-400. [CrossRef]

9. Gür, T.M. Permselectivity of zeolite filled polysulfone gas separation membranes. J. Membr. Sci. 1994, 93, 283-289. [CrossRef]

10. Süer, M.G.; Baç, N.; Yilmaz, L. Gas permeation characteristics of polymer-zeolite mixed matrix membranes. J. Membr. Sci. 1994, 91, 77-86. [CrossRef]

11. Hussain, M.; König, A. Mixed-Matrix Membrane for Gas Separation: Polydimethylsiloxane Filled with Zeolite. Chem. Eng. Technol. 2012, 35, 561-569. [CrossRef]

12. Zarshenas, K.; Raisi, A.; Aroujalian, A. Mixed matrix membrane of nano-zeolite NaX/poly (ether-blockamide) for gas separation applications. J. Membr. Sci. 2016, 510, 270-283. [CrossRef]

13. Dechnik, J.; Gascon, J.; Doonan, C.; Janiak, C.; Sumby, C. Mixed-Matrix Membranes. Angew. Chem. 2017, 56, 9292-9310. [CrossRef] [PubMed]

14. Nejad, M.; Asghari, M.; Afsari, M. Investigation of Carbon Nanotubes in Mixed Matrix Membranes for Gas Separation: A Review. ChemBioEng Rev. 2016, 3, 276-298. [CrossRef]

15. Khan, M.M.; Filiz, V.; Bengtson, G.; Shishatskiy, S.; Rahman, M.M.; Lillepaerg, J.; Abetz, V. Enhanced gas permeability by fabricating mixed matrix membranes of functionalized multiwalled carbon nanotubes and polymers of intrinsic microporosity (PIM). J. Membr. Sci. 2013, 436, 109-120. [CrossRef] 
16. Sutrisna, P.D.; Hou, J.; Li, H.; Zhang, Y.; Chen, V. Improved operational stability of Pebax-based gas separation membranes with ZIF-8: A comparative study of flat sheet and composite hollow fibre membranes. J. Membr. Sci. 2017, 524, 266-279. [CrossRef]

17. Li, T.; Pan, Y.; Peinemann, K.V.; Lai, Z. Carbon dioxide selective mixed matrix composite membrane containing ZIF-7 nanofillers. J. Membr. Sci. 2013, 425, 235-242. [CrossRef]

18. Bushell, A.F.; Budd, P.M.; Attfield, M.P.; Jones, J.T.; Hasell, T.; Cooper, A.I.; Bernanrdo, P.; Bazzarelli, F.; Clarizia, G.; Jansen, J. Nanoporous organic polymer/cage composite membranes. Angew. Chem. 2013, 52, 1253-1256. [CrossRef]

19. Şen, D.; Kalıpçılar, H.; Yilmaz, L. Development of polycarbonate based zeolite 4A filled mixed matrix gas separation membranes. J. Membr. Sci. 2007, 303, 194-199. [CrossRef]

20. Zhao, Z.; Jiang, J. POC/PIM-1 mixed-matrix membranes for water desalination: A molecular simulation study. J. Membr. Sci. 2020, 608, 118173. [CrossRef]

21. Yu, G.; Li, Y.; Wang, Z.; Liu, T.X.; Zhu, G.; Zou, X. Mixed matrix membranes derived from nanoscale porous organic frameworks for permeable and selective $\mathrm{CO}_{2}$ separation. J. Membr. Sci. 2019, 591, 117343. [CrossRef]

22. Begni, F.; Paul, G.; Lasseuguette, E.; Mangano, E.; Bisio, C.; Ferrari, M.C.; Gatti, G. Synthetic Saponite Clays as Additives for Reducing Aging Effects in PIM1 Membranes. ACS Appl. Polym. Mater. 2020, 2, 3481-3490. [CrossRef]

23. Lau, C.H.; Konstas, K.; Doherty, C.M.; Smith, S.J.; Hou, R.; Wang, H.; Carta, M.; Yoon, H.; Park, J.; Freeman, R.-M.; et al. Tailoring molecular interactions between microporous polymers in high performance mixed matrix membranes for gas separations. Nanoscale 2020, 12, 17405-17410. [CrossRef] [PubMed]

24. Smith, S.J.D.; Lau, C.H.; Mardel, J.I.; Kitchin, M.; Konstas, K.; Ladewig, B.P.; Hill, M.R. Physical aging in glassy mixed matrix membranes; tuning particle interaction for mechanically robust nanocomposite films. J. Mater. Chem. A. 2016, 4, 10627-10634. [CrossRef]

25. Lau, C.H.; Konstas, K.; Thornton, A.W.; Liu, A.C.; Mudie, S.; Kennedy, D.F.; Howard, S.C.; Hill, A.J.; Hill, M. Gas Separation Mem-branes Loaded with Porous Aromatic Frameworks that Improve with Age. Angew. Chem. 2015, 54, 2669-2673. [CrossRef]

26. Khdhayyer, M.; Bushell, A.F.; Budd, P.M.; Attfield, M.P.; Jiang, D.; Burrows, A.D.; Esposito, E.; Bernardo, E.; Monteleone, M.; Fuoco, A.; et al. Mixed matrix membranes based on MIL-101 metal-organic frameworks in polymer of intrinsic microporosity PIM-1. Sep. Purif. Technol. 2019, 212, 545-554. [CrossRef]

27. Alberto, M.; Bhavsar, R.; Luque-Alled, J.M.; Vijayaraghavan, A.; Budd, P.M.; Gorgojo, P. Impeded physical aging in PIM-1 membranes containing graphene-like fillers. J. Membr. Sci. 2018, 563, 513-520. [CrossRef]

28. Huang, J.; Turner, S.R. Hypercrosslinked Polymers: A Review. Polym. Rev. 2017, 58, 1-41. [CrossRef]

29. Tsyurupa, M.; Davankov, V. Hypercrosslinked polymers: Basic principle of preparing the new class of polymeric materials. React. Funct. Polym. 2002, 53, 193-203. [CrossRef]

30. Dawson, R.; Cooper, A.I.; Adams, D.J. Nanoporous organic polymer networks. Prog. Polym. Sci. 2012, 37, 530-563. [CrossRef]

31. Yang, Y.; Tan, B.; Wood, C.D. Solution-processable hypercrosslinked polymers by low cost strategies: A promising platform for gas storage and separation. J. Mater. Chem. A. 2016, 4, 15072-15080. [CrossRef]

32. Hou, R.; O'Loughlin, R.; Ackroyd, J.; Liu, Q.; Doherty, C.M.; Wang, H.; Hill, M.R.; Smith, S.J.D. Greatly Enhanced Gas Selectivity in Mixed-Matrix Membranes through Size-Controlled Hyper-cross-linked Polymer Additives. Ind. Eng. Chem. Res. 2020, 59, 13773-13782. [CrossRef]

33. Lau, C.H.; Mulet, X.; Konstas, K.; Doherty, C.M.; Sani, M.-A.; Separovic, F.; Hill, M.R.; Wood, C.D. Hypercrosslinked Additives for Ageless Gas-Separation Membranes. Angew. Chem. Int. Ed. 2016, 55, 1998-2001. [CrossRef]

34. Mitra, T.; Bhavsar, R.S.; Adams, D.; Budd, P.M.; Cooper, A.I. PIM-1 mixed matrix membranes for gas separations using costeffective hypercrosslinked nanoparticle fillers. Chem. Commun. 2016, 52, 5581-5584. [CrossRef] [PubMed]

35. Budd, P.M.; McKeown, N.B.; Ghanem, B.S.; Msayib, K.J.; Fritsch, D.; Starannikova, L.; Belov, N.; Sanfirova, O.; Yampolskii, Y.; Shantarovich, V. Gas permeation parameters and other physicochemical properties of a polymer of intrinsic microporosity: Polybenzodioxane PIM-1. J. Membr. Sci. 2008, 325, 851-860. [CrossRef]

36. Thommes, M.; Kaneko, K.; Neimark, A.V.; Olivier, J.P.; Rodriguez-Reinoso, F.; Rouquerol, J.; Sing, K.S.W. Physisorption of Gases, With Special Reference to the Evaluation of Surface Area and Pore Size Distribution (IUPAC Technical Report). Pure Appl. Chem. 2015, 87, 1051. [CrossRef]

37. Paul, G.; Begni, F.; Melicchio, A.; Golemme, G.; Bisio, C.; Marchi, D.; Cossi, M.; Marchese, L.; Gatti, G. Hy-per-Cross-Linked Polymers for the Capture of Aromatic Volatile Compounds. ACS Appl. Polym. Mater. 2020, 2, 647-658. [CrossRef]

38. Liu, Y.; Fan, X.; Jia, X.; Zhang, B.; Zhang, H.; Zhang, A.; Zhang, Q. Hypercrosslinked polymers: Controlled preparation and effective adsorption of aniline. J. Mater. Sci. 2016, 51, 8579-8592. [CrossRef]

39. Socrate, G. Infrared and Raman Characteristic Group Frequencies: Tables and Charts, 3rd ed.; Wiley \& Sons Ltd.: West Sussex, UK, 2004.

40. Coates, J. Interpretation of infrared spectra, a practical approach. In Encyclopedia of Analytical Chemistry: Applications, Theory and Instrumentation; Meyers, R.A., Ed.; John Wiley \& Sons Ltd.: Hoboken, NJ, USA, 2000.

41. Tsyurupa, M.P.; Blinnikova, Z.K.; Davidovich, Y.A.; Lyubimov, S.E.; Naumkin, A.V.; Davankov, V.A. On the nature of "func-tional groups" in non-functionalized hypercrosslinked polystyrenes. React. Funct. Polym. 2012, 72, 973-982. [CrossRef]

42. Olah, G.A.; Kobayashi, S.; Tashiro, M. Aromatic Substitution. XXX.1 23Friedel-Crafts Benzylation of Benzene and Toluene with Benzyl and Substituted Benzyl Halides. J. Am. Chem. Soc. 1972, 21, 94. 
43. Errahali, M.; Gatti, G.; Tei, L.; Paul, G.; Rolla, G.A.; Canti, L.; Fraccarollo, A.; Cossi, M.; Comotti, A.; Sozzani, P.; et al. Microporous Hyper Cross-Linked Aromatic Polymers Designed for Methane and Carbon Dioxide Adsorption. J. Phys. Chem. C 2014, 118, 28699-28710. [CrossRef]

44. Van der Made, A.W.; Van der Made, R.H. A Convenient Procedure for Bromomethylation of Aromatic Compounds. Selective Mono-, Bis-, or Trisbromomethylation. J. Org. Chem. 1993, 58, 1262-1263. [CrossRef]

45. Bastani, D.; Esmaeili, N.; Asadollahi, M. Polymeric mixed matrix membranes containing zeolites as a filler for gas separation applications: A review. J. Ind. Eng. Chem. 2013, 19, 375-393. [CrossRef]

46. Swaidan, R.; Ghanem, B.; Pinnau, I. Fine-Tuned Intrinsically Ultramicroporous Polymers Redefine the Permeability/Selectivity Upper Bounds of Membrane-Based Air and Hydrogen Separations. ACS Macro Lett. 2015, 4, 947-951. [CrossRef]

47. Harms, S.; Rätzke, K.; Faupel, F.; Chaukura, N.; Budd, P.M.; Egger, W.; Ravelli, L. Aging and Free Volume in a Polymer of Intrinsic Microporosity (PIM-1). J. Adhes. 2012, 88, 608-619. [CrossRef] 